\title{
Septodermoplasty: Make It Easier
}

\author{
Chol Ho Shin $(\mathbb{D})$ and Yong Ju Jang $(\mathbb{D}$ \\ Department of Otorhinolaryngology-Head and Neck Surgery, Asan Medical Center, University of Ulsan College of Medicine, \\ Seoul, Korea
}

\section{비중격 식피술 집도에 도움이 되는 유용한 수술 기법들}

신철호 · 장용주

울산대학교 의과대학 서울아산병원 이비인후과학교실

\author{
Received July 9,2021 \\ Revised August 25, 2021 \\ Accepted September 1, 2021 \\ Address for correspondence \\ Yong Ju Jang, MD \\ Department of Otorhinolaryngology- \\ Head and Neck Surgery, \\ Asan Medical Center, \\ University of Ulsan \\ College of Medicine, \\ 88 Olympic-ro 43-gil, Songpa-gu, \\ Seoul 05505, Korea \\ Tel $+82-2-3010-3712$ \\ Fax +82-2-489-2773 \\ E-mail jangyj@amc.seoul.kr
}

\begin{abstract}
Septodermoplasty (SDP) is a technique that presents a surgical option for the treatment of recalcitrant epistaxis from hereditary hemorrhagic telangiectasia. It involves the removal of affected nasal epithelium, replacing it with a split thickness skin graft (STSG). However, the inherent challenges with SDP are that owing to the floppy and unstable nature of the STSG, especially if simultaneously grafting the lateral nasal wall in addition to the septum and nasal floor, there is a risk of inadvertently stripping and displacing the STSG from its intended position. In this article we offer some techniques that utilize microdebrider for addressing mucosal lesions and fixate silastic sheet on floppy STSG as a scaffold to make it firm and easy to handle in order to hold the graft right in place.
\end{abstract}

Korean J Otorhinolaryngol-Head Neck Surg 2021;64(10):766-70

Keywords Epistaxis; Hereditary hemorrhagic telangiectasia; Skin grafting.

\section{서 론}

유전성 출혈성 모세혈관 확장증(hereditary hemorrhagic telangiectasia, HHT)은 상염색체 우성 유전 질환으로, 동정 맥의 기형으로 인해 대부분의 환자에서 비점막의 사소한 자 극에 반복적인 비출혈이 발생하며 쉽게 지혈되지 않는 것이 특징적이다.1) 초기 진단과 치료가 늦을수록 전기 소작술을 반복적으로 시행하게 되고 이로 인해 난치성 비중격 천공이 발생할 수 있으며, ${ }^{2)}$ 이를 예방하기 위한 수술적 치료로 비중 격 식피술이 널리 이용되고 있다. 비중격 식피술은 1962년 Saunders ${ }^{3}$ 가 HHT의 치료를 위해 도입한 이후 널리 이용되 고 있는 수술적 치료 방법이다. 수술 방법으로는 주로 연골막 바깥층(supraperichondrial plane)의 점막을 큐렛으로 제거

This is an Open Access article distributed under the terms of the Creative Commons Attribution Non-Commercial License (https://creativecommons.org/licenses/by-nc/4.0) which permits unrestricted non-commercial use, distribution, and reproduction in any medium, provided the original work is properly cited.
한 뒤 허벅지에서 채취한 피부 이식편을 점막 결손부위에 위 치시키고, 비전정부와 이식편을 봉합하여 고정한 뒤 실라스틱 시트(silicon silasic sheet)나 거즈 패킹을 시행하는 방법이 고 전적으로 시행되어 왔다. ${ }^{4-6)}$ 그러나 좁은 비강 내 출혈이 다량 발생하는 상황에서 원하는 부위의 점막을 정확히 제거하는 것은 어려운 일이고, 피부 이식편이 원하는 곳에 위치하도록 조작하는 것도 쉽지 않다. 뿐만 아니라 실라스틱 시트, 거즈 패킹을 시행하는 과정에서 이식편이 움직일 수 있으며, 이식 편의 고정과 지지가 제대로 되지 않아 원하는 곳에 적절한 생 착이 이루어지지 않을 수 있다. 이를 극복하기 위한 방법들이 여러 연구자들에 의해 시도되었는데, Rimmer와 Lund그는 수술 중 시야를 확보하면서도 원하는 부위의 점막을 정확히 제거하기 위해 microdebrider를 이용하여 점막을 제거하는 방식을 보고한 바 있다. 피부 이식편을 삽입할 때에도 접착성 파라핀 드레싱에 이식편을 붙여 비강 내에 삽입한 후 드레싱 만을 조심스럽게 제거하여 피부 이식편을 삽입할 때 비교적 
쉽게 조작할 수 있도록 하였다. Bastianelli와 Kilty ${ }^{8}$ 는 연골 막 위층으로 점막을 박리하는 방법을 사용하였고, 패킹 없이 fibrin sealant $\left(\right.$ Tissel $\left.^{\circledR}\right)$ 만을 이용하여 이식편을 비강 내에 고정하였다.

본 저자는 정확한 병변 제거를 위해 microdebrider를 도입 했을 뿐만 아니라, 실라스틱 시트와 피부 이식편을 미리 봉합 사로 고정하여 비강 내에 삽입하는 방법을 채택하였다. 이는 기존 문헌들에서는 사용된 적이 없는 방법으로, 기존의 방법 들에 비해 이식편의 조작이 용이하고 정확하게 이식편을 고정 및 지지할 수 있는 장점이 있어 이에 대해 소개하고자 한다.

\section{방 법}

본원에서 저자는 2009년 4월부터 2018년 4월까지 조절되지 않는 반복적인 출혈이 발생한 12 명의 HHT 환자에게 재수술 을 포함하여 13 건의 비중격 식피술을 시행하였으며 11건에 서는 양측, 2 건에서는 일측 비중격 식피술을 시행하였다. 4 명 에서는 수술 전 비중격의 천공이 있는 상태였으며, 그 중 2명 에서는 비중격 식피술과 비중격 천공 봉합술을 동시에 시행 하였다. 또한 1 건의 경우 비성형술과 동시에 시행하였다. 수술 후 평균 47.81개월(1.37-126.53개월)간 경과 관찰을 시행하였 다. 경과 관찰 기간이 12 개월 미만인 환자 3 명에게는 전화 설 문을 통해 재출혈 여부를 확인하였다.

\section{수술 준비}

수술은 전신마취하에 0 도 내시경을 이용하여 진행하였다. 환자는 앙와위 자세로 위치시켜 수술을 진행하였다. 수술 전 양측 비강에 1:200000 에피네프린과 2\% 리도카인 혼합 용 액을 적신 거즈을 삽입한 후 10-15분 뒤 제거하였다. 피부 이 식편을 채취하기 위해 서혜부와 허벅지의 제모를 시행하였 다. 우측 슬관절은 굴곡시키고 고관절은 굴곡 및 외회전 시 킨 뒤 베타딘 용액을 이용하여 공여부의 소독을 시행하였다.

\section{병변의 제거}

비강 점막을 제거하기 전 내시경을 이용하여 제거할 범위 를 확인하였다. 전방으로는 비전정 피부와 점막 경계의 $5 \mathrm{~mm}$ 전을 경계로 삼았고, 비중격 위아래 전체를 대상으로 하였다. 필요시에는 비강저부 전체를 제거 대상으로 하였으며, 비강 측벽의 제거가 필요한 경우 하비갑개와 중비갑개 내측면을 제거 대상으로 하였다. 다만 하비도와 중비도 내측으로 굽어 들어가는 부위의 점막은 제거하지 않았는데, 이는 해당 부위 에 이식편을 이식하기가 어렵고 이식했을 때 비루관과 부비동 개구복합체(osteomeatal complex)의 배출로를 막을 위험성
이 있기 때문이다. 해당 범위에서 혈관의 돌출이 확인되는 부 위를 $4 \mathrm{~mm}$ 일자형 microdebrider (Medtronic, Minneapolis, $\mathrm{MN}, \mathrm{USA}$ )를 사용하여 $3000 \mathrm{rpm}$ 으로 전부 제거하였다. 이 때 연골막이 드러나면 더 깊게 진행하지 않고 연골막보다 바 깥쪽의 부분만을 제거하도록 주의하였다. 특히 비중격 식피술 의 재수술을 시행할 때는 이전에 이식한 이식편이 연골막과 단단히 붙어있기 때문에 박리가 어려우므로 microdebrider 을 사용한 방법이 더욱 유용하였다. 점막을 제거하고 나서 에피네프린 거즈를 비강 내에 다시 삽입하여 지혈을 시행하 였으며, 지혈이 이루어지는 동안 피부 이식편을 채취하였다.

\section{피부 이식편 채취}

피부 이식편은 주로 우측 허벅지의 내측에서 채취하였으나, 흥터가 있는 등 피부 상태가 적합하지 않을 때에는 쇄골 주변 부나 좌측 허벅지에서 이식편을 채취하기도 하였다. Zimmer air dermatome (Zimmer Surgical Inc., Warsaw, IN, USA) 을 이용하여 0.010-0.025 인치 두께의 부분층 피부이식편 (split-thickness skin graft)를 채취하였다. CT상에서 비중격 과 비강 외측벽의 높이 및 깊이, 비저의 넓이 및 깊이를 측정 하였으며, 이에 맞춰 실라스틱 시트를 재단하여 실제 비강 내 에 삽입해보는 방식으로 이식이 필요한 부위의 넓이를 확인 하였다. 이 넓이에 맞춰서 이식편을 채취하였으며, 작게는 $4 \times$ $8 \mathrm{~cm}$ 에서 넓게는 $8 \times 15 \mathrm{~cm}$ 의 크기로 채취를 시행한 뒤 양측 비강에 나누어 이식하였다.

\section{실라스틱 시트 - 피부 이식편 복합 이식편 디자인 및 비강 내 이식}

병변의 범위에 맞게 실리콘 실라스틱 시트를 디자인한 뒤 피부 이식편을 그 위에 올리고 여러 개의 $26 \mathrm{G}$ 바늘로 우선 고정하였다. 이 때 피부 이식편의 진피 방향이 위를 향하고 표피 방향은 실라스틱 시트와 접하도록 하였다. 피부 이식편 을 실라스틱 시트의 모양에 맞게 iris scissors로 다듬어준 뒤 가장자리를 따라 6-0 vicryl로 봉합하여 실라스틱 시트와 피 부 이식편이 떨어지지 않도록 고정하였으며, 중앙 부위가 뜨 지 않도록 가운데에도 수 회 봉합을 시행하였다. 이 때 피부 이식편에는 절개창을 만들지 않고 그대로 사용하였다(Fig. 1). 이식편과 실라스틱 시트의 모양은 이식이 필요한 병변의 모 양과 범위에 따라 조절하였다(Fig. 2). 비중격 점막만 덮어도 충분할 경우에는 약 $3 \times 4 \mathrm{~cm}$ 크기의 물방울 모양이나 사각 형 모양으로 실라스틱 시트를 디자인하였고 해당 모양에 맞 추어 피부 이식편을 다듬었다. 비강저부와 비갑개 내측벽까 지도 덮어야 할 경우 U자 모양으로 이식편을 만들어줄 필요 가 있는데, 우선 길게 만들어둔 피부 이식편의 일부와 실라 
스틱 시트를 봉합사로 고정한 뒤(Fig. 3A) 비강 내에 들어갈 흡수성 비강 충전재를 미리 이식편에 올렸다(Fig. 3B). 그리 고 피부 이식편의 잉여 부분으로 충전재를 감싼 뒤 끝부분을

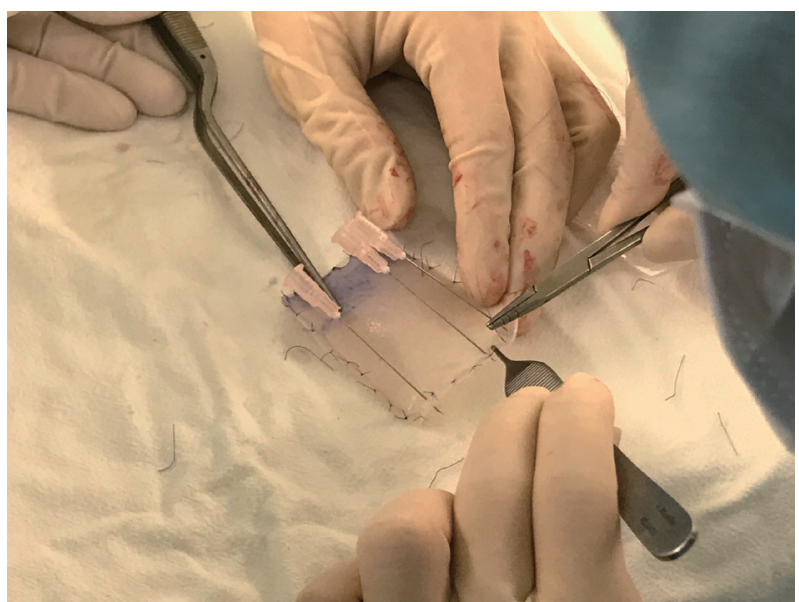

Fig. 1. The STSG is placed on silastic sheet and fixated with fine gauged needles to a silastic sheet. After trimming out, STSG was secured to the silastic sheeting with 6-0 vicryl tacking sutures. STSG, split-thickness skin graft.

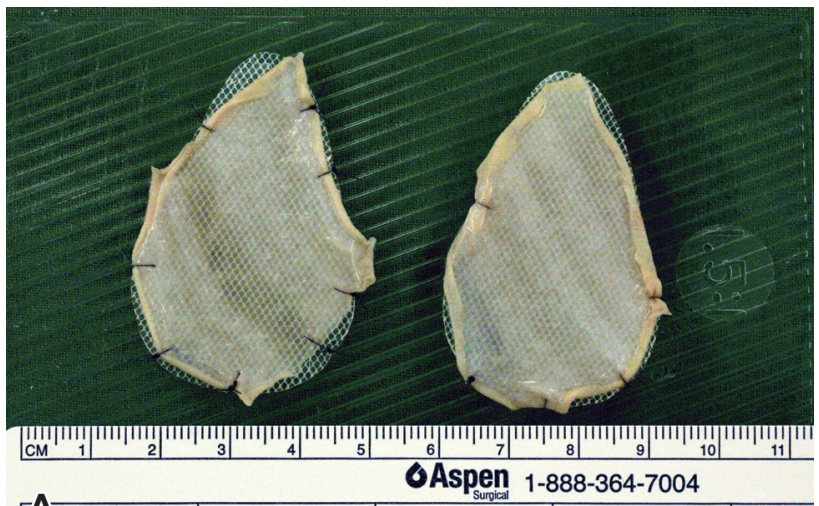

A

Aspen 1-888-364-7004

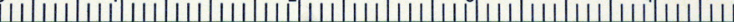

Fig. 2. Silastic sheet was designed to fit the mucosal defect, and STSG was laid on it with dermal side up and epidermal side in contact with the sheet. STSG was sutured on the silastic sheet along the peripheral edges and additional sutures were also done in the center. Shape of the graft differs according to the shape of mucosal defect. A: Waterdrop-shaped graft. B: Rectangular-shaped graft. STSG, split-thickness skin graft.
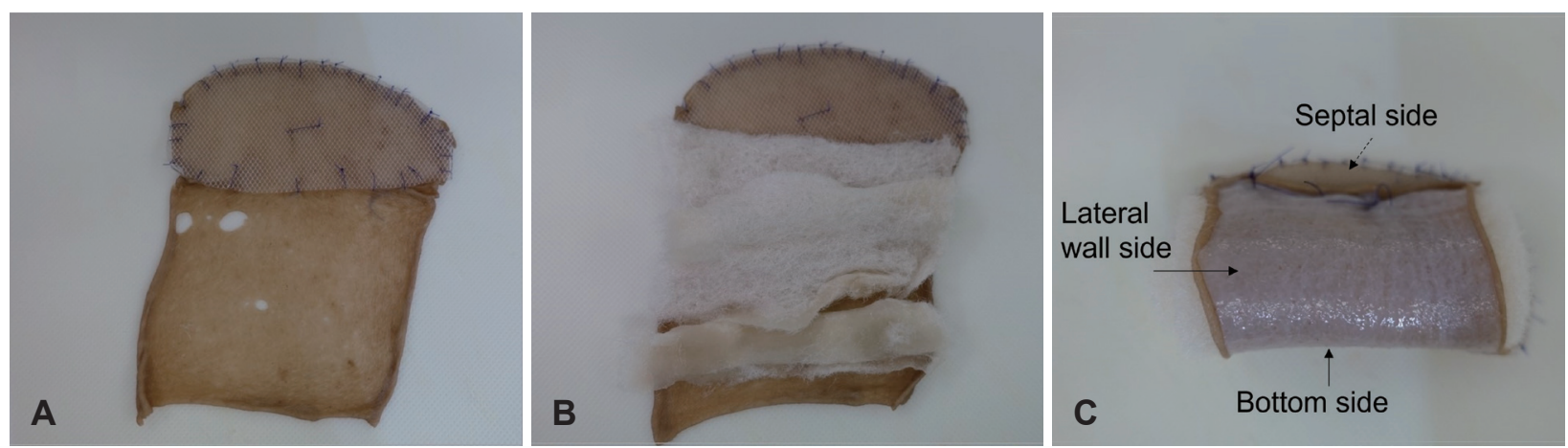

Fig. 3. The upper third of the skin graft is sutured on designed silastic sheet. A: Absorbable nasal packing is placed on epidermal side of the skin graft. B: The packing is rolled inside the skin, and peripheral edge of the skin is sutured to the other side so that it forms a shape of cylinder. C: When inserted in the nasal cavity, side on which silastic sheet is fixated goes to the septum side and bottom of U-shape goes to the nasal floor side. 

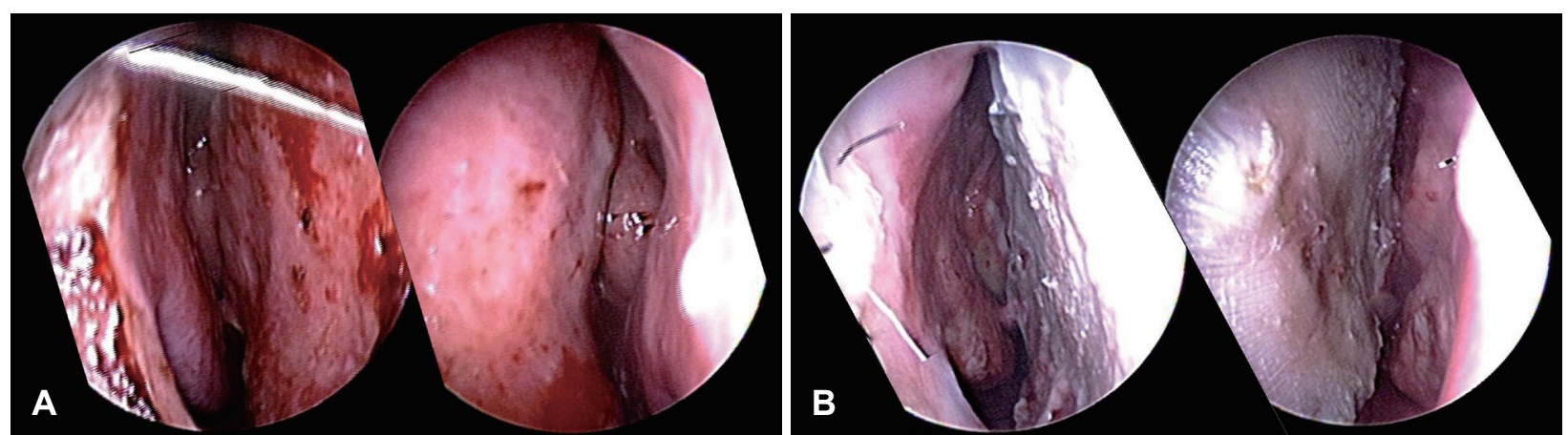

Fig. 4. Comparison between preoperative and postoperative endoscopic view of both nasal cavity. Endoscopic exam before septodermoplasty (A) shows engorging vessels on both side of septum. On endoscopic exam of postoperative day 25 (B), both side of nasal septum is well covered with skin graft.

합사를 우선 제거한 뒤, 전방에 위치하여 비전정부위와 연결 된 6-0 vicryl을 iris scissors를 이용하여 제거하였다. 봉합사 가 제거된 곳으로 freer elevator를 삽입하여 실라스틱 시트 를 이식편으로부터 조심스럽게 들어올린 뒤 0도 내시경을 그 안으로 삽입하였다. 생리식염수로 적신 cotton pledget을 안 으로 넣은 뒤 freer elevator를 이용해 앞뒤로 움직여 주변부 공간을 넓혀주었고, 더 나아가 실라스틱 시트가 이식편으로 부터 완전히 떨어지도록 하였다. 가장자리 부분의 봉합된 부 분 또한 cotton pledget을 조심스럽게 움직여 이식편의 손상 없이 끊어낼 수 있었다. 이후 헤드라이트로 비강 내를 관찰 하면서 cotton pledget으로 이식편을 눌러 고정한 다음, 실라 스틱 시트를 tooth forceps를 이용하여 조심스럽게 빼냈다. 이러한 과정을 통하여 이식편의 이탈 없이 실라스틱 시트를 제거할 수 있다.

실라스틱 시트의 제거 후에는 내시경을 이용하여 이식편이 잘 생착되었는지 확인하였다. 하비도와 중비도 위치에 붙지 않고 떠있는 이식편이 남아있게 되는데, 이 부위는 내시경으 로 관찰하며 iris scissors로 제거하였다.

\section{경과 관찰}

수술 이후 수 주간 Mupirocin nasal ointment ${ }^{\circledR}$ (Kolmar Korea, Sejong, Korea)을 비강 전정부에 도포하도록 지시하 였다. 수술 후 3 일, 6 일, 10 일째에 경과 관찰을 시행하였으며 (Fig. 4A), 수술 후 2주째에 실라스틱 시트를 제거한 뒤 3주, 4주 째에도 경과 관찰을 시행하였다(Fig. 4B). 이후로는 환자 의 상태에 따라 간격을 달리하여 경과 관찰을 시행하였다.

\section{결 과}

경과 관찰 기간 동안 이식편은 모든 환자에서 성공적으로 생착되었다. 수술 후 1 년 이상 경과가 지나고 나서 확인한 결 과 열 명의 환자들은 재출혈이 없었거나 감소하였다고 보고
하였다. 그 외 두 명의 환자에서는 이식이 이루어지지 않고 남은 부위에서 조절되지 않는 코피가 다시 발생하여 재수술 을 시행하였다. 한 명은 비중격 식피술을 재시행받았고, 다른 한 명은 성형외과 협의하 유리 전완 요골 피판을 이용한 비강 재건술을 시행받았다. 재수술후에는 두 명 모두 출혈의 재발 이 없었다.

결론적으로 실라스틱 시트와 피부 이식편을 봉합하여 복 합 이식편을 만든 뒤 비강 내에 이식하는 술식을 이용해 이 식편을 쉽게 조작할 수 있고 적절한 이식편의 지지와 고정을 이룰 수 있으며, 수술 후 생착률 및 예후 또한 우수한 것으로 생각된다.

\section{Acknowledgments}

None.

\section{Author Contribution}

Conceptualization: Yong Ju Jang. Data curation: Chol Ho Shin. Resources: Yong Ju Jang. Visualization: Chol Ho Shin. Writingoriginal draft: Chol Ho Shin. Writing — review \& editing: Yong Ju Jang.

\section{ORCIDs}

Yong Ju Jang https://orcid.org/0000-0001-7631-0388 Chol Ho Shin https://orcid.org/0000-0003-0955-1397

\section{REFERENCES}

1) Guttmacher AE, Marchuk DA, White RI Jr. Hereditary hemorrhagic telangiectasia. N Engl J Med 1995;333(14):918-24.

2) Yang CJ, Lee BJ, Jang YJ. Usefulness of septodermoplasty in hereditary hemorrhagic telangiectasia. Korean J OtorhinolaryngolHead Neck Surg 2015;58(5):330-6.

3) Saunders WH. Hereditary hemorrhagic telangiectasia, its familial pattern, clinical characteristics, and surgical treatment. Arch Otolaryngol 1962;76(3):245-60.

4) Goldsmith MM, Fry TL. Tips on septal dermoplasty. Laryngoscope 1987;97(8 Pt 1):994-5.

5) Fiorella ML, Ross D, Henderson KJ, White RI Jr. Outcome of septal dermoplasty in patients with hereditary hemorrhagic telangiectasia. Laryngoscope 2005;115(2):301-5.

6) Ichimura K, Kikuchi H, Imayoshi S. A new method of nasal 
dermoplasty (MW grafting method) in patients with large septal perforation. Laryngoscope 2011;121(8):1715-7.

7) Rimmer J, Lund VJ. A modified technique for septodermoplasty in hereditary hemorrhagic telangiectasia. Laryngoscope 2014;124(1):
$67-9$.

8) Bastianelli M, Kilty SJ. Technique modifications for septodermoplasty: An illustrative case. J Otolaryngol Head Neck Surg 2015;44:59. 